\title{
Insetos visitantes de gomas exsudadas por Terminalia argentea Mart \& Zucc (Combretaceae)
}

\author{
Samuel Boff ${ }^{1}$, Gustavo Graciolli², Amanda Galdi Boaretto ${ }^{1} \&$ Maria Rita Marques $^{1}$
}

${ }^{1}$ Programa de Pós-graduação em Biologia Vegetal, Departamentos de Biologia e de Morfofisiologia, Universidade Federal do Mato Grosso do Sul (UFMS), Caixa Postal 549, 79000-000 Campo Grande-MS.

${ }^{2}$ Programa de Pós-graduação em Ecologia e Conservação, Departamento de Biologia, UFMS. ggraciolli@yahoo.com.br

\begin{abstract}
Visiting insects of exudated gums by Terminalia argentea Mart. \& Zucc (Combretaceae). One of the ephemeral food sources that insects may use is the exudated gums from plants. In May 2005, in an area of Cerrado from Campo Grande, Mato Grosso do Sul, Brazil, insects visiting an exudation structure of an individual of Terminalia argentea Mart \& Zucc (Combretaceae) were observed. Nineteen species were identified, mainly Trigona branneri (Cockerel) and Mesembrinella bicolor (Fabricius). All visitors had been observed collecting or ingesting the gum. Visitation time and behavior of the most abundant species were reported. Samples of exudates showed a low concentration of proteins and reducing sugars and high concentration of complex carbohydrate, allowing infer that visitors of $T$. argentea seek the gum a food resource of high molecular weight that contributes to the storage of energy reserves.
\end{abstract}

KEYWORDS. Apidae; ephemeral resource; feeding habitat; Mesembrinelliinae.

\begin{abstract}
RESUMO. Insetos visitantes de gomas exsudadas por Terminalia argentea Mart \& Zucc (Combretaceae). Uma das fontes efêmeras de alimento que os insetos podem utilizar são as gomas exsudadas por plantas. No mês de maio de 2005, em uma área de cerrado no município de Campo Grande, Mato Grosso do Sul, foram observados insetos visitando as estruturas de exsudação em um indivíduo de Terminalia agentea Mart \& Zucc (Combretaceae). Foram registradas 19 espécies, principalmente Trigona branneri (Cockerell) e Mesembrinella bicolor (Fabricius). Todos os visitantes foram observados coletando ou ingerindo a goma exsudada. Observações sobre o horário de visitação e comportamento das espécies mais abundantes são relatadas. As amostras de exsudatos apresentaram baixa concentração de proteínas e açucares redutores e alta concentração de carboidratos complexos, permitindo inferir que os visitantes de T. argentea buscam na goma um recurso alimentar de alta massa molecular que contribui para o armazenamento de reservas energéticas.
\end{abstract}

PALAVRAS-CHAVE. Apidae; hábito alimentar; Mesembrinellinae; recurso efêmero.

Insetos visitantes de flores, como abelhas e vespas (Hymenoptera), borboletas (Lepidoptera, Nymphalidae), moscas (Diptera) e besouros (Coleoptera), apresentam estreita relação com tipos florais que garantem a polinização dessas flores enquanto coletam recursos (Proctor et al. 1996). Outros visitantes podem visitar flores sem efetivar a polinização ou procurar outras fontes de recursos vegetais como nectários extra-florais (Faegri \& van Der Pij1 1979) excretas de homópteros, seivas de frutos e resinas (Roubik 1992). Entre os diversos grupos de insetos, alguns são especializados na coleta de exsudatos ricos em carboidratos como resinas, óleos, gomas e tiloses, além daqueles ricos em compostos voláteis para atração sexual, como é o caso de muitos látexes (Chow et al.2005).

As estruturas de oclusão do parênquima xilemático e a secreção de exsudatos por plantas ocorrem em resposta à idade, injúrias mecânicas ou infecções, entre outros fatores (Weiss 1997, Rioux et al. 1998). Exsudatos estão entre os recursos efêmeros que podem ser utilizados por um grande número de insetos (principalmente holometábolos) e outros artrópodos (Yamamoto et al. 2005).

Informações acerca da utilização de exsudatos como recurso alimentar de artrópodos na Região Neotropical são escassas, com exceção de dados relativos aos besouros da família Nitidulidae, principalmente as espécies de Cryptarchinae, que são conhecidas por se alimentarem de exsudatos secretados após injúria causada por grandes escarabeídeos em raízes (Cline \& Calton 2004).

Neste trabalho são relatadas as espécies de insetos visitantes com observações de comportamento e período de visitação em gomas exsudadas por um indivíduo de T. argentea em uma área de cerrado do Mato Grosso do Sul.

Termina argentea Mart \& Zucc (Combretaceae) é uma espécie arbórea ereta de cerrado que atinge entre 5 e $15 \mathrm{~m}$ de altura, com casca enegrecida. A floração ocorre entre agosto e setembro e a frutificação entre abril e setembro. No cerrado é encontrada em fisionomia do tipo cerradão, borda de cordilheira e em solos arenosos (Pott \& Pott 1994). 
A coleta de dados ocorreu em fragmento de cerrado (cerradão cf. Eiten 1979) de cerca de 600 hectares na EMBRAPA Gado de Corte (20 27' S e 54 3' W, 530m altitude), em Campo Grande, MS. O clima segundo Koppen está na faixa entre mesotérmico úmido sem estiagem e temperaturas superiores a $22^{\circ} \mathrm{C}$ no mês seco e o clima tropical úmido com estação chuvosa no verão e seca no inverno, com temperatura média ente $19^{\circ} \mathrm{C}$ e $25^{\circ} \mathrm{C}$. A observação de um indivíduo de $T$. argenta que apresentava dano mecânico no caule do qual exsudava uma grande quantidade de goma ocorreu em 16 de maio de 2006, entre $7 \mathrm{~h} 45 \mathrm{~min}$ e $18 \mathrm{~h}$ com observações de 45 minutos em cada hora. Os registros referentes ao táxon, horário e comportamento de forrageamento foram realizados para cada visitante. Para a coleta de parte dos visitantes foi utilizada uma rede entomológica e para os das ordens Blattaria e Coleoptera uma pinça anatômica. Quando necessário os espécimens foram encaminhados a especialistas para identificação e depositados na coleção zoológica da Universidade Federal de Mato Grosso do Sul e nas coleções de origem dos especialistas. As amostras de goma foram retiradas do caule da árvore com auxílio de pinça, abaixo do ponto de exsudação.

Em laboratório, foram realizadas análises de porcentagem de água (Marques et al. 2006), concentração de proteínas solúveis (Bradford 1976), carboidratos totais (Dubois et al. 1956), e redutores (Somogyi 1945) presentes nas amostras $(n=6)$ de exsudatos. Para as análises bioquímicas as amostras foram diluídas em tampão fosfato de sódio $0,1 \mathrm{M}, \mathrm{pH} 7,0$, para investigação do valor energético da goma a partir do conteúdo de água, proteínas totais, carboidratos totais e açúcares redutores.

Dezenove espécies de visitantes de 13 famílias de Insecta foram encontradas nos exsudatos de T. argentea (Tabela I). Os visitantes foram observados em processo de alimentação diretamente sobre o recurso. Trigona branneri Cockerell, 1912 (Hymenoptera, Apidae) além de ingerir o exsudato ainda na forma líquida também o armazenou seco nas corbículas.

Trigona branneri e Mesembrinella bicolor (Fabricius, 1805) (Diptera, Calliphoridae) foram as espécies com maior número de registros, seis e 15 , respectivamente. A visitação

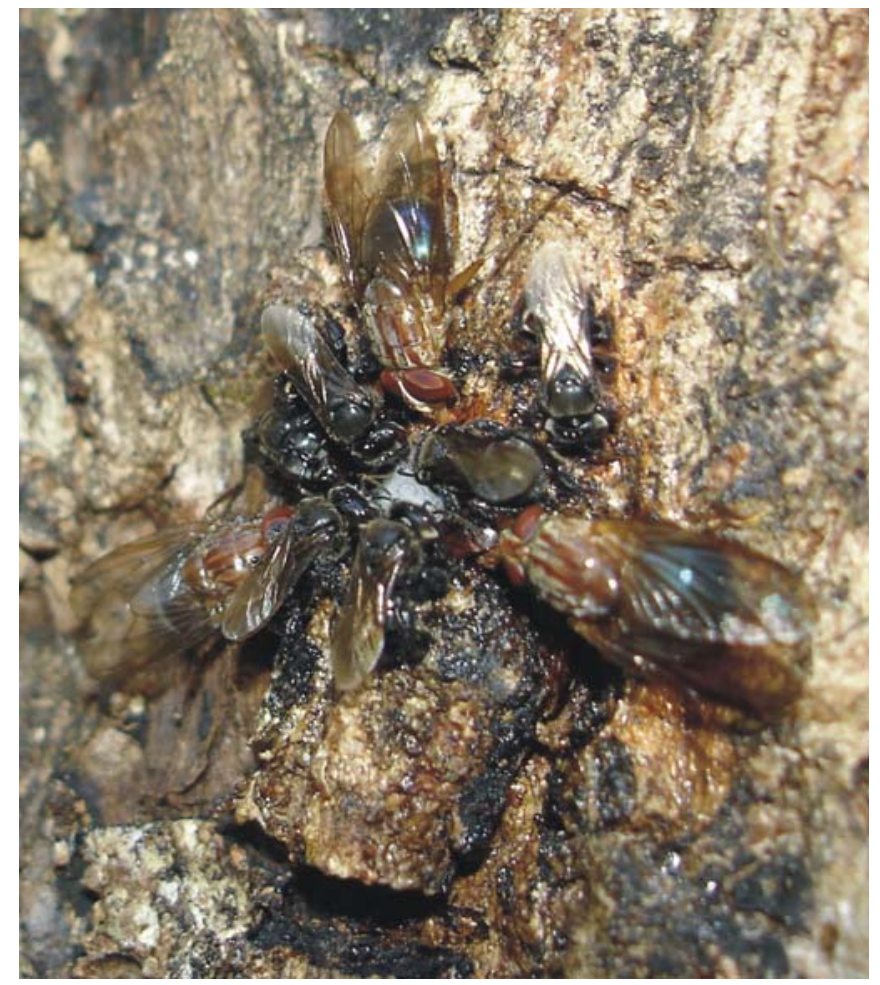

Fig. 1. Trigona branneri e Mesembrinella bicolor se alimentando de exsudato sobre o tronco de Terminalia argenta.

de T. branneri ocorreu entre às $7 \mathrm{~h} 51 \mathrm{~min}$ e $12 \mathrm{~h} 45 \mathrm{~min}$, enquanto que $M$. bicolor foi mais freqüente entre $7 \mathrm{~h} 51 \mathrm{~min}$ e $10 \mathrm{~h} 10 \mathrm{~min}$ e entre $15 \mathrm{~h} 10 \mathrm{~min}$ e $17 \mathrm{~h} 15 \mathrm{~min}$, sendo este último o visitante mais comum durante o período de observação, com aproximadamente $25 \%$ do total de visitas ao longo do dia, exceto nos horários com temperaturas mais elevadas.

Nem todos os visitantes apresentaram o mesmo comportamento de visita. Trigona branneri forragearam em grupo deslocando outros visitantes, exceto $M$. bicolor. Na presença de T. branneri, outros visitantes pousaram a alguns centímetros do local de exsudação e se aproximaram lentamente do recurso, no entanto os ninfalídeos visitaram o recurso

Tabela I. Insetos visitantes de goma exsudada por um indivíduo de Terminalia argêntea Mart \& Zucc (Combretaceae), no Cerrado brasileiro.

\begin{tabular}{cc}
\hline Ordem/Família & Espécie \\
\hline Blattaria/ Blattelidae & Não determinada \\
Coleoptera / Nitidulidae e Silvanidae & Não determinadas \\
Hymenoptera/ Vespidae & Não determinada \\
Apidae & Trigona branneri Cockerell, 1912 \\
Lepidoptera/ Nymphalidae & Callicore astarte selina (Guenée, 1872) e Hamadryas amphinome amphinome (Linnaeus, 1767) \\
Diptera/ Ropalomeridae & Ropalomera femorata (Fabricius, 1805) e Ropalomera clavipes (Fabricius, 1805) \\
Diptera/ Neriidae & Glyphidops (Glyphidops) sp. e Glyphidops (Oncopsia) sp. \\
Diptera/ Drosophilidae & Não determinada \\
Diptera/ Odiniidae & Odinia sp. 1 e Odinia sp. 2 \\
Diptera/ Muscidae & Dolichophaonia paranaensis Carvalho, 1993 e Polietina orbitalis (Stein, 1904) \\
Diptera/ Calliphoridae & Mesembrinella bicolor (Fabricius, 1805) \\
Diptera/ Sarcophagidae & Oxysarcodexia avuncula (Lopes, 1933) e Oxysarcodexia admixta (Lopes, 1933)
\end{tabular}


Tabela II. Análises de conteúdo de água, proteínas totais, carboidratos totais e açúcares redutores de amostras de exsudatos de Terminalia argentea Mart \& Zucc (Combretaceae) no Cerrado brasileiro.

\begin{tabular}{ccccc}
\hline Amostras & Água (\%) & $\begin{array}{c}\text { Proteína Solúvel } \\
\text { Total }(\%)\end{array}$ & $\begin{array}{c}\text { Carboidratos } \\
\text { Totais }(\%)\end{array}$ & $\begin{array}{c}\text { Açúcares } \\
\text { redutores }(\%)\end{array}$ \\
\hline 1 & 4,11 & 0,208 & 23,649 & 0,825 \\
2 & 9,33 & 0,172 & 9,760 & 0,054 \\
3 & 4,75 & 0,172 & 17,640 & 1,234 \\
4 & 7,36 & 0,146 & 11,180 & 1,198 \\
5 & 0,16 & 0,114 & 28,576 & 0,130 \\
6 & 8,43 & 0,118 & Não determinado & 0,019 \\
\hline
\end{tabular}

somente na ausência de outros indivíduos. Na ausência de $T$. branneri, M. bicolor apresentou comportamento agressivo, ao procurar deslocar da fonte de alimento outros indivíduos de sua espécie e de outros visitantes.

A porcentagem de água encontrada nos exsudatos pode indicar o tempo de exposição no ambiente, daí sua alta variação. Os exsudatos apresentaram baixa concentração de proteínas e açucares redutores por grama de peso seco (Tabela II). Como já observado por outros autores, as gomas em geral apresentam uma baixa concentração de proteínas, com a maioria delas conjugadas a polissacarídeos que formam proteoglicanas (Marques \& Xavier-Filho 1991, Marques et al. 1992, Rioux et al. 1998). Por outro lado, foi encontrada alta proporção de carboidratos totais nas amostras analisadas (Tabela II). Os resultados indicam que as espécies visitantes de T. argentea buscam recursos energéticos, como as cadeias de polissacarídeos de alta massa molecular o que contribui para o armazenamento de reservas energéticas para os seus visitantes.

Agradecimentos. Aos pesquisadores Marcelo Oscar Bordignon (Departamento de Biologia, UFMS) pela cessão da foto, Arnildo Pott (EMBRAPA) pela identificação de T. argenta, e Cátia Mello Patiú (Museu Nacional do Rio de Janeiro), Sílvio S. Nihei (Departamento de Zoologia, USP), Rosaly Ale-Rocha (INPA), Ângelo Pires do Prado (Departamento de Parasitologia, UNICAMP) e Olaf H. Hendrik Mielke, Gabriel Melo, Claudio José Barros de Carvalho e Sionei Ricardo Bonatto (Departamento de Zoologia, UFPR), pela identificação dos insetos.

\section{REFERÊNCIAS}

Bradford, M. M. 1976. A rapid and sensitive method for the quantification of microgram quantities of protein utilizing the principle of protein-dye binding. Analitical Biochemistry 72: $248-254$.

Chow, J. K.; Y. Akhtar \& M. B. Isman. 2005. The effects of larval experience with a complex plant latex on subsequent feeding and oviposition by the cabbage looper moth: Trichoplusia ni (Lepidoptera: Noctuidae). Chemoecology 15: 129-133.

Cline, A. R. \& C. E. Carlton. 2004. Review of Lasiodactylus Perty, with descriptions of three new species (Coeloptera: Nitidulidae: Nitidulinae). The Coleopterists Bulletin 58: 355-368.

Dubois, M.; K. A. Gilles; J. K. Hamilton; P. A. Rebers \& F. Smith. 1956. Colorimetric method for determination of sugar and related substances. Analytical Chemistry 28: 350-356.

Eiten, G. 1979. Formas fisionômicas do Cerrado. Revista Brasileira de Botânica 2: 139-148.

Faegri, K. \& L. Van Der Pijl. 1979. The Principles of Pollination Ecology. Sinauer Associates, London, 224 p.

Marques, M. R.; L. Albuquerque \& J. Xavier-Filho. 1992. Antimicrobial and Inseticidal activies of cashew tree gum exudate. Annual Applied Biology 121: 371-377.

Marques, M. R.; M. S. Buckeridge; M. R. Braga \& S. M. C. Dietrich. 2006. Characterization of an extracellular endopolygalacturonase from the saprobe Mucor ramosissimus and its action as trigger of defensive response in tropical plants. Mycopathologia 62: 337346.

Marques, M. R. \& J. Xavier Filho. 1991. Enzymatic and inhibitory activities of Cashew Tree gum exudate. Phytochemistry 30: 14311433.

Pott A. \& V. J. Pott. Plantas do Pantanal. Empresa Brasileira de Pesquisas Agropecuária, Centro de Pesquisa Agropecuária do Pantanal-Corumbá, MS: Embrapa- SPI, 1994. 320 p.

Proctor, M.; P. Yeo \& A. Lack. 1996. The Natural History of Pollination. Timber Press. Portland, Oregon. 487 p.

Rioux, D.; M. Nicole; M. Simard \& G. B. Ouellette. 1998. Immunocytochemical Evidence that Secretion of Pectin Occurs During Gel (Gum) and Tylosis Formation in Trees. Biochemistry and Cell Biology (Phytopathology) 88: 494-505.

Roubik, W. D. 1992. Ecology and natural history of tropical bees. Cambridge Tropical Biology series, Cambridge 514 p.

Somogyi, M. 1945. A new reagent for the determination of sugar. Journal Biological Chemistry 160: 61-68.

Weis, W. I. 1997. Cell surface carbohydrate recognition by animal and viral lectins. Current Opinion in Structural Biology 7: 624630.

Yamamoto, J.; T. Kakutani \& T. Nishida. 2005. Influence of resource abundance on the structure of the insect community attracted to fermented tree sap. Ecology Research 20: 405-414. 